\title{
The negative and positive effects of trauma resulting from cancer - the role of personality and rumination
}

\author{
Nina Ogińska-Bulik \\ Institute of Psychology, University of Lodz, Lodz, Poland
}

BACKGROUND

Personality and cognitive engagement, including eventrelated rumination, play essential roles in the negative and positive outcomes of experienced trauma. The aim of the study was to establish the role of personality traits and rumination in the occurrence of posttraumatic stress disorder (PTSD) symptoms and posttraumatic growth (PTG).

PARTICIPANTS AND PROCEDURE

Sixty persons, aged $18-78$ years $(M=50.40, S D=17.74)$, who had experienced malignant tumours in the craniofacial area, i.e. the lips, palate, parotid gland, eye, nasopharynx, nasal cavity, middle ear and paranasal sinuses, were examined. The majority of respondents $(68.30 \%)$ were women. The subjects were surveyed with the Impact of Event Scale-R (IES-R), the Posttraumatic Growth Inventory (PTGI), the NEO-Five Factor Personality (NEO-FFI), and the Event Related Rumination Inventory (ERRI).
RESULTS

Both PTSD symptoms and PTG were observed in the examined group. Almost $77.00 \%$ of participants demonstrated at least a medium degree of PTSD. Twenty three percent of subjects revealed a high level of PTG. Both intrusive and deliberate ruminations were related to the presence of PTSD symptoms and PTG. No direct relationship was found between personality dimensions and the negative and positive outcomes of trauma. Neuroticism, which is related to intrusive rumination, affects PTSD symptoms. Conscientiousness, which is related to deliberate ruminations, affects posttraumatic growth.

\section{CONCLUSIONS}

Personality has an indirect impact on the negative and positive consequences of trauma via rumination over the experienced event.

\section{KEY WORDS}

personality; cancer; rumination; posttraumatic growth; posttraumatic stress disorders

CORResPonding AUthor - Prof. Nina Ogińska-Bulik, Institute of Psychology, University of Lodz, 10/12 Smugowa Str., 91-433 Lodz, Poland, e-mail: noginska@uni.lodz.pl

AUthors' CONTRIBUtion - A: Study design - B: Data collection - C: Statistical analysis - D: Data interpretation .

E: Manuscript preparation · F: Literature search · G: Funds collection

TO CITE THIS ARTICLE - Ogińska-Bulik, N. (2017). The negative and positive effects of trauma resulting from cancer-

the role of personality and rumination. Current Issues in Personality Psychology, 5(4), 232-243.

RECEIVED 30.11.2016 · REVIEWED 01.02.2017 · ACCEPTED 21.02.2017 · PUBLISHED 27.04.2017 


\section{BACKGROUND}

\section{NEGATIVE AND POSITIVE EFFECTS OF THE STRUGGLE WITH CANCER}

Cancer is regarded as a life-threatening disease, and as such may be treated as a potentially traumatic event. This much is indicated in the DSM-5, the latest classification of mental disorders (APA, 2013). Studies indicate that the experience of cancer encourages the symptoms included in posttraumatic stress disorder (PTSD) (Cordova, Studs, Hann, Jacobsen, \& Andrykowski, 2000; Shelby \& Golden-Kreutz, 2008; Widera, Juczyński, \& Popiela, 2003). PTSD has been identified in 10-30\% of cancer patients (Kangas, Henry, \& Bryant, 2002).

However, it has been shown that the struggle with cancer can also result in the development of posttraumatic growth (PTG), manifested as positive changes in self-perception, relations with others or philosophy of life (Tedeschi \& Calhoun, 1996, 2004).

Studies have confirmed the presence of PTG among oncological patients (Bellizzi \& Blank, 2006; Carboon, Anderson, Pollard, Szer, \& Seymour, 2005; Mystakidou, Tsilika, Parpa, Galanos, \& Vlahos, 2008; Ogińska-Bulik, 2010, 2016; Park, Chmielewski, $\&$ Blank, 2010). Among the many factors determining the negative and positive effects of posttraumatic changes, a particularly important role is played by the character of the individual, manifested as the existing personality traits and the degree of cognitive engagement in processing the trauma, including changes of core beliefs and the presence of rumination over the experienced trauma (Calhoun \& Tedeschi, 2006; Calhoun, Cann, \& Tedeschi, 2010).

\section{PERSONALITY, RUMINATION, PTSD AND PTG}

The personality characteristics favouring the occurrence of PTSD symptoms include negative emotionality, particularly experiencing anxiety, anger and hostility (treated as categories of traits), neuroticism, avoidance, difficulty in expressing emotions (Jakšić, Brajković, Ivezić, Topić, \& Jakovljević, 2012) and low psychological resistance to experienced events expressed in emotional reactivity (Zawadzki, Kaczmarek, \& Strelau, 2009).

Posttraumatic stress disorder symptoms in cancer patients were associated with such personality traits as anxiety, defensiveness, symptoms of depression (Jeantieu et al., 2014; Phipps, Jurbergs, \& Long, 2009), hopelessness/helplessness and type C personality (Perez et al., 2014).

Among the personality dimensions comprising the Big Five model, neuroticism is believed to have particular significance in the occurrence of PTSD and the maintenance of its symptoms (Brodaty, Joffe, Luscombe, \& Thompson, 2004; Dudek, 2003; Dudek
\& Koniarek, 2004; Lawrence \& Fauerbach, 2003). It is assumed that neurotics experience stronger emotions under stress than emotionally stable individuals, and these emotions last longer, which favours the occurrence of PTSD symptoms. Positive correlations have also been found between PTSD and introversion (Holeva \& Tarrier, 2001). In contrast, extraversion is treated as a protective factor against the development of PTSD (Dudek, 2003; Jakšić et al., 2012; Strelau, Zawadzki, Oniszczenko, Sobolewski, \& Pawłowski, 2004). Data concerning the relationship between conscientiousness and PTSD are equivocal; some studies show a positive relationship between them (Klonowicz \& Eliasz, 2004), while others indicate a negative relationship (Jakšić et al., 2012).

However, extraversion and openness to new experience have been found to have the greatest influence on the emergence of PTG (Linley \& Joseph, 2004; Sheikh, 2004; Tedeschi \& Calhoun, 1996). Other studies have also indicated that agreeableness (Tashiro \& Frazier, 2003) and conscientiousness (Karanci et al., 2012) also play important roles. However, there is a lack of clear evidence about the role of neuroticism in the development of positive outcomes from trauma. Although Shakespeare-Finch, Gow, and Smith (2005) report no relationship between neuroticism and PTG, they do indicate that the other dimensions of the Big Five personality model may play a role in occurrence of positive posttraumatic changes. Other studies (Linley \& Joseph, 2004) have indicated that neuroticism has a negative influence on PTG, in that it inhibits the development of positive changes.

An important role in the development of negative and positive posttraumatic changes is also played by the cognitive activity of the individual, particularly the process of rumination (Calhoun \& Tedeschi, 2006; Calhoun, Cann, \& Tedeschi, 2010; Ogińska-Bulik, 2015; Tedeschi \& Calhoun, 1996, 2004). As a result of the event, the individual not only experiences negative emotions, but also considers and remembers the experienced event, discusses it, analyses it and gradually gives it new meaning. This type of cognitive activity is primarily intended to enable the cognitive processing of the trauma, which in turn can lead to a reduction in PTSD symptoms and the prevalence of positive posttraumatic changes.

Rumination is not a unique concept. Most often it is understood as contemplation or "chewing over" specific content, which often occurs for no apparent reason. Nolen-Hoeksema (2000) considers ruminative thinking to be a passive process which serves to focus attention on perceived negative emotions. From this perspective, rumination is associated primarily with the occurrence of the symptoms of pathology, particularly depression and anxiety. Rumination may be regarded as a process involving repeated thoughts about the experienced traumatic event, which may be of a negative, neutral or even positive character 
(Calhoun \& Tedeschi, 1998). This process includes two types of rumination (Cann et al., 2011). One, known as intrusive rumination or intrusive thinking, is more destructive. It is composed of automatically appearing thoughts that the individual is not able to control, and which are not linked to attempts to solve the problem. The second form, deliberate rumination, is more constructive. It encourages the individual to analyse the situation, and to identify ways to resolve it. Intrusive rumination usually favours the maintenance of PTSD symptoms (Cann et al., 2011; Ehlers \& Clark, 2000; Ehring \& Ehlers, 2014). In turn, deliberate rumination serves as a means of "working through the trauma" and acts as a factor encouraging the development of PTG. At the same time it is noted that both types of ruminations are important for the occurrence of PTG (Calhoun et al., 2010; Cann et al., 2011; Taku, Calhoun, Cann, \& Tedeschi, 2008). ${ }^{1}$

A body of available data, although not all of it, indicates that rumination, especially deliberate rumination, is also related to the occurrence of PTG following the experience of cancer (Chan, Ho, Tedeschi, \& Leung, 2011; Morris \& Shakespeare-Finch, 2011). In addition, Polish studies have also identified it in people with various types of cancer (Ogińska-Bulik, 2016), and parents caring for children with cancer (Ogińska-Bulik \& Ciechomska, 2016).

Other studies indicate a lack of any relationship between rumination and PTG, or even a negative relationship between the variables. Long-term studies on leukaemia patients have found that intrusive rumination occurring during the course of treatment does not predict the occurrence of PTG at the end of treatment (Carboon et al., 2005). Similar results have been achieved in groups of patients with colorectal cancer (Salsman, Segerstrom, Brechting, Carlson, $\&$ Andrykowski, 2009). In another study of cancer patients, Park et al. (2010) report a negative relationship between intrusive rumination and the occurrence of positive changes following the trauma. These equivocal results of studies into the relationship between rumination and the outcomes of trauma associated with the experience of cancer have encouraged further exploration in this area.

It may also be supposed that the nature of the undertaken cognitive activity, rumination over the experienced event in this case, depends on the personal characteristics of the individual. Personality may then influence the positive or negative outcomes of the experienced event, be it directly, or indirectly through the process of rumination.

The aim of the present study was to determine the influence of personality and rumination on the occurrence of negative and positive outcomes of trauma following cancer. As indicators, PTSD symptoms were regarded as negative consequences and PTG as positive ones. The study addresses the following research questions:
- What degree of negative and positive outcomes from the experienced event did the subjects demonstrate?

- Are sex, age and the time elapsed from the diagnosis of cancer associated with the consequences of the experienced trauma?

- In which way are personality and rumination associated with the intensity of the positive and negative outcomes of the experienced event?

The adopted research model is based on the PTG concept (Calhoun \& Tedeschi, 2006; Calhoun et al., 2010) and assumes that both personality and rumination influence both the positive and negative effects of the experienced trauma. It is expected that neuroticism will encourage intrusive rumination and the occurrence of PTSD; however, extraversion and openness to new experiences will be associated with deliberate rumination and the occurrence of PTG.

\section{PARTICIPANTS AND PROCEDURE}

The study group included 60 individuals aged 18 to 78 years $(M=50.40, S D=17.74)$, who were diagnosed with a form of cancer in the craniofacial area (i.e. lip, palate, parotid gland, eye, nasopharynx, nasal cavity, paranasal sinuses and inner ear) and who regarded the illness as a traumatic situation. The study took place in one of the health care centres dealing with facial reconstruction in Lodz, Poland, during the medical appointment after surgery. The majority of those studied were women (68.30\%). The participants were informed of the aim of the study and were assured of their anonymity. Permission for the study was given by the appropriate bioethics committee. ${ }^{2}$

The subjects were surveyed using the Impact of Event Scale-R, the Posttraumatic Growth Inventory, the NEO Five-Factor Inventory and Event Related Rumination Inventory.

The revised version of the Impact of Event Scale (IES-R), by Weiss and Marmar (1997), adapted into Polish by Juczyński and Ogińska-Bulik (2009), was used to determine the subjective sense of discomfort connected with the experienced event. It consists of 22 items (e.g. "Any reminder brought back feelings about it") and measures the general level of PTSD and its three dimensions: intrusion, hyperarousal and avoidance. The participants indicate responses using a 5-point Likert scale (from 0 - not at all to 4 - extremely). The Polish version of the IES-R has acceptable psychometric parameters; its reliability measured with Cronbach's $\alpha$ coefficient is .75.

The Posttraumatic Growth Inventory (PTGI), developed by Tedeschi and Calhoun (1996) and adapted to Polish conditions by Ogińska-Bulik and Juczyński (2010), consists of 21 statements describing various positive changes resulting from the experience of a traumatic event ("I have changed my priorities 
regarding that which is important in life"). The participants respond to the statements providing answers from 0 (not having experienced such change) to 5 (having experienced such change to a great degree). Polish version of the PTGI measures four factors constituting posttraumatic growth: changes in self-perception, changes in relations with others, greater appreciation of life and spiritual changes. The reliability coefficient of the Polish version of the PTGI is high (Cronbach's $\alpha=.93$ ) and similar to that for the original version.

The NEO Five-Factor Inventory (NEO-FFI), developed by Costa and McCrae (1989), in the Polish adaptation by Zawadzki, Strelau, Szczepaniak, and Śliwińska (1998), was used to measure five dimensions of personality: neuroticism, extraversion, openness to experience, agreeableness and conscientiousness. It comprises 60 statements ("I am not a worrier"), which are rated on a five-point scale (from 1 - decidedly disagree to 5 - completely agree). The psychometric profile of the Polish adaptation of the NEO-FFI is satisfactory (Cronbach's $\alpha$ ranges from .60 to .82).

The Event Related Rumination Inventory (ERRI), developed by Cann and co-workers (2011) and adapted into Polish by Ogińska-Bulik and Juczyński (2015), consists of two subscales with 10 item each. The first ("I thought about the event when I did not mean to") covers intrusive ruminations, which are uncontrolled, and the second one ("I thought about whether I could find meaning from my experience”) covers deliberate (reflective) ones. The respondents rate the items on a 4-point Likert scale (from 0 - not at all to 3 - often). The scores are computed separately for each subscale. The inventory has very good psychometric properties. In the Polish version Cronbach's $\alpha$ is .96 for intrusive ruminations and .92 for deliberate ruminations.

\section{RESULTS}

The analysis was performed in accordance with the formulated research questions, according to the following steps. The mean values of the analysed variables were calculated, and it was tested whether sex, age or time elapsed from the diagnosis of cancer was associated with the degree of PTSD or PTG. Following this, structural modelling was used to examine the role played by personality and rumination in the fostering of positive or negative outcomes of the experienced trauma.

The obtained results had a normal distribution. The SPSS package with AMOS version 24 was used for all calculations. The results of the IES-R $(M=43.63$, $S D=18.10)$ did not differ from standard observations (Juczyński \& Ogińska-Bulik, 2009). A more detailed analysis found that a significant majority of respondents $(76.70 \%)$ demonstrated medium or strong symptoms of PTSD, while the remaining $23.30 \%$ demonstrated a low level of symptoms. ${ }^{3}$

The intensity of the PTSD symptoms varied according to sex. Women experienced significantly higher intensity of symptoms $(M=47.75, S D=14.79)$ than men $(M=34.73, S D=21.56, t=2.73, p<.010)$. Another differentiating factor was time elapsed from the traumatic event. Those who had experienced it within the five years before the test demonstrated a significantly higher level of PTSD symptoms $(M=50.43, S D=16.95)$ than those who had experienced it earlier, i.e. more than five years before the study $(M=35.85, S D=16.38, t=3.33, p<.001)$. Age appeared to have no effect on the degree of PTSD symptoms $(r=-.02)$.

The mean PTG demonstrated by the subjects $(M=59.41, S D=18.77)$ corresponded to a value of five sten, which indicates a medium result. According to the norms designed for the Polish version of the PTGI (Ogińska-Bulik \& Juczyński, 2010), the results indicate that $33.30 \%$ of those studied demonstrated a low level of PTG, $43.40 \%$ a medium level and $23.30 \%$ a high level.

Sex had a statistically significant influence on the intensity of positive posttraumatic changes, i.e. PTG (men: $M=51.52, S D=20.62$; women: $M=62.56$, $S D=17.00, t=-2.18, p<.050)$. The time from the occurrence of the illness was not associated with the degree of PTG (shorter, i.e. less than five years: $M=62.59, S D=19.12$; longer, i.e. five years and over: $M=55.03, S D=17.85)$. Age did not differentiate between the intensity of PTG $(r=.03)$.

The next step was to analyse the data associated with the relationship structure between variables by structural equation modelling (path analysis). Various models were tested according to the goodness of fit between them and the observed variance-covariance matrix. The introduced variables were used to search the structure of the relationship between personality, rumination, PTSD and PTG. PTSD and PTG were the dependent variables, personality dimensions were treated as independent variables, and ruminations were treated as mediating variables.

Figures 1-6 present the models fulfilling the theoretical, logical and economic requirements complying with the established empirical requirements. All obtained values reflected their best possible fit with the tested parameters, i.e. the "ideal model".

As can be seen in Figure 1, neuroticism is directly associated with intrusive rumination, which also appears to be associated with the occurrence of PTSD symptoms. Although neuroticism does not seem to have a direct influence on the negative effects of the experienced trauma, it appears to act indirectly by favouring the development of intrusive rumination.

As shown in Figures 2 and 3, extraversion and openness to experience are not directly associated with the intensity of PTSD, but are negatively asso- 


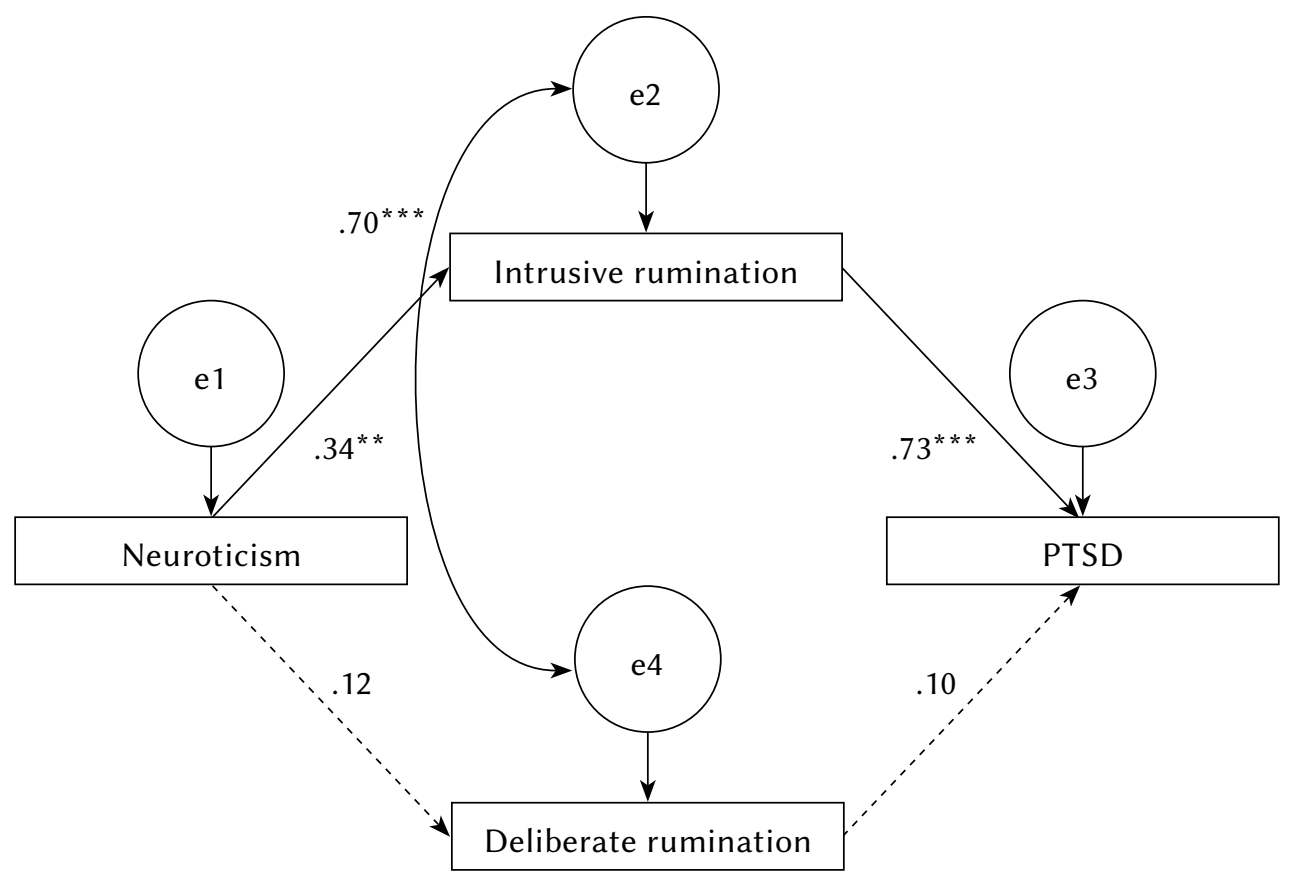

Values:

$\chi=0.61, d f=1, p=.436$

$\mathrm{CFI}=1.000$

RMSEA Steiger-Lind's $=0.000$

${ }^{* * *} p<.001,{ }^{* *} p<.010$

Figure 1. The relationship between neuroticism, rumination and PTSD.

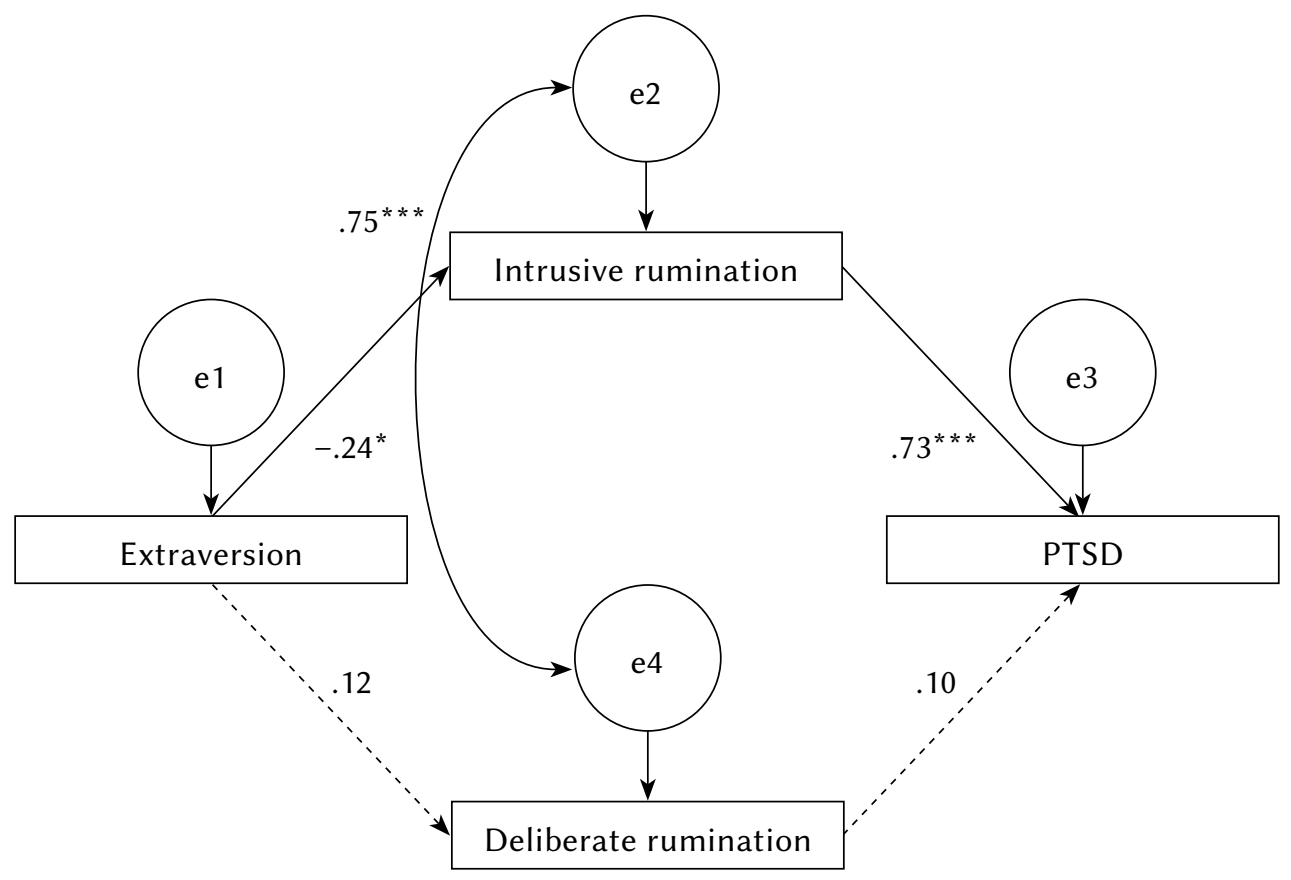

Values:

$\chi=.30, d f=1, p=.584$

$\mathrm{CFI}=1.000$

RMSEA Steiger-Lind's $=0.000$

${ }^{* * *} p<.001,{ }^{* *} p<.050$

Figure 2. The relationship between extraversion, rumination and PTSD. 


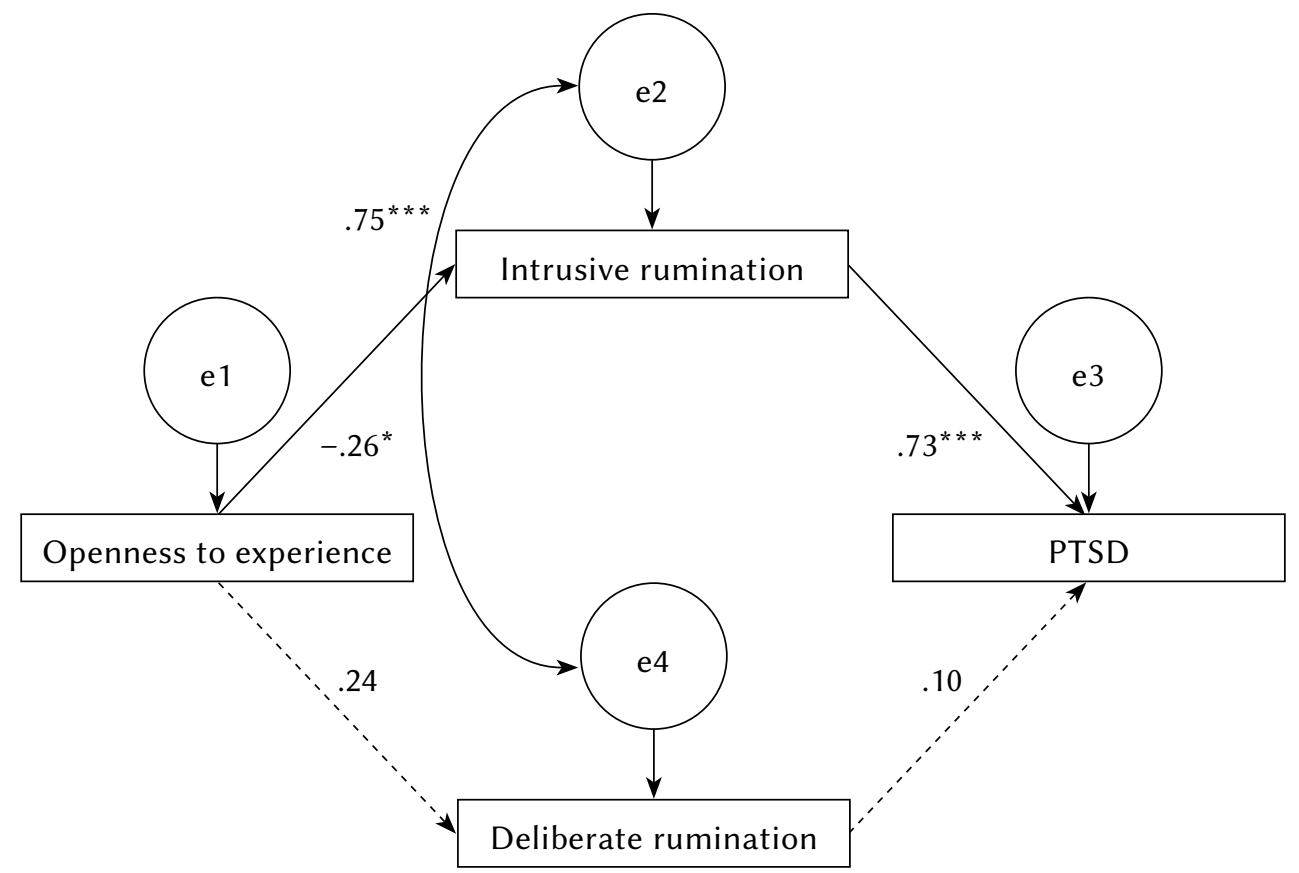

Values:

$\chi=0.01, d f=1, p=.909$

$\mathrm{CFI}=1.000$

RMSEA Steiger-Lind's $=0.000$

${ }^{* * *} p<.001,{ }^{*} p<.050$

Figure 3. The relationship between openness to experience, rumination and PTSD.

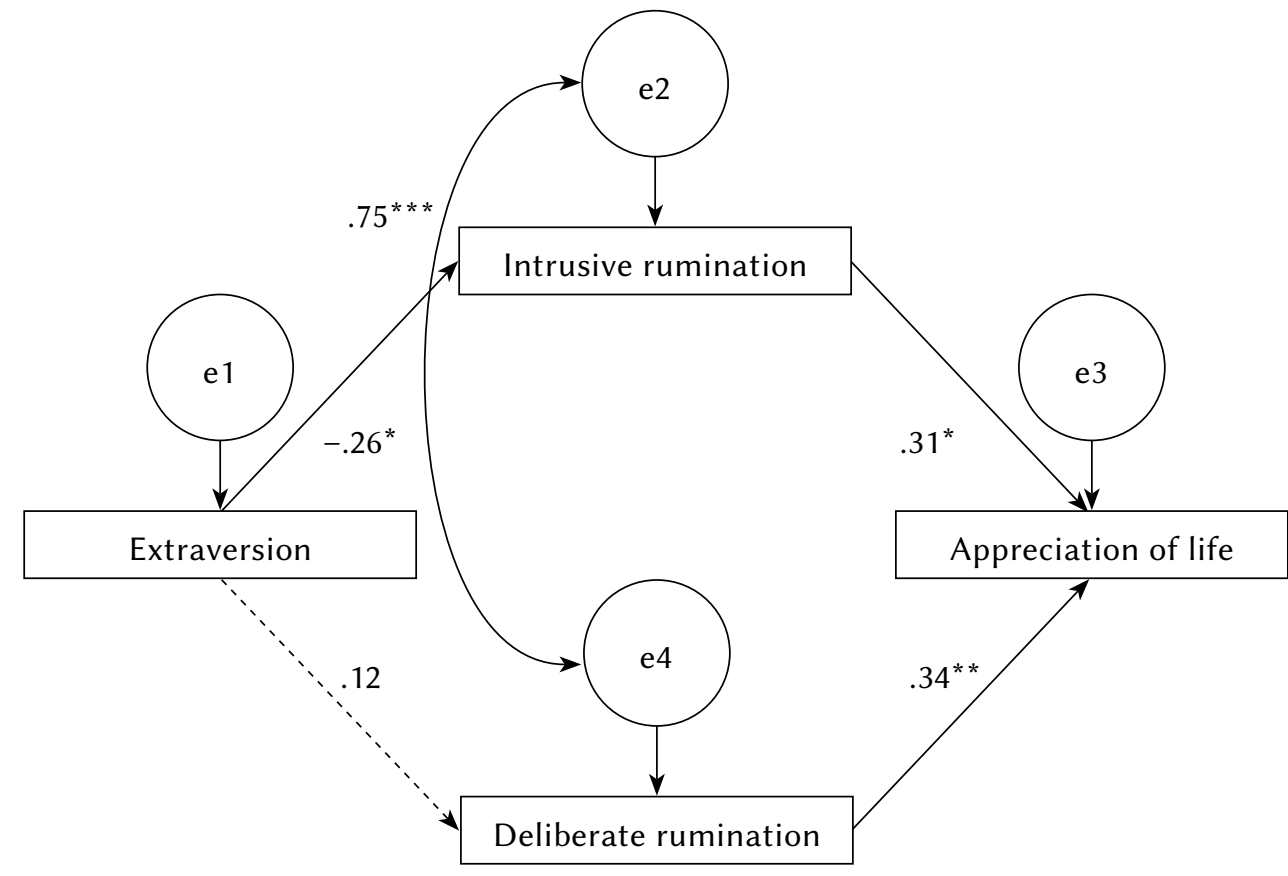

Values:

$\chi=1.16, d f=1, p=.281$

$\mathrm{CFI}=0.998$

RMSEA Steiger-Lind's $=0.053$

${ }^{* * *} p<.001,{ }^{* *} p<.010,{ }^{*} p<.050$

Figure 4. The relationship between extraversion, rumination and appreciation of life. 


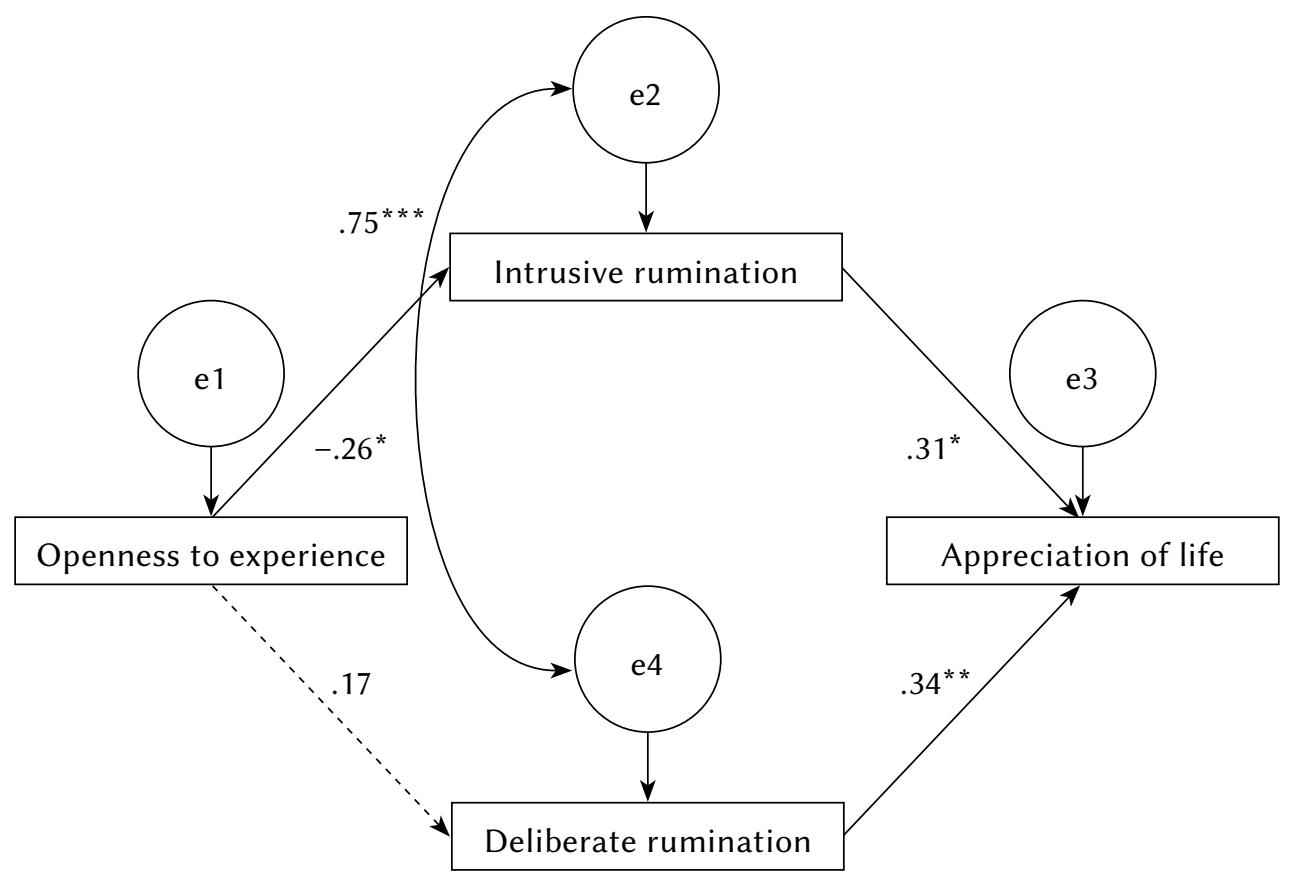

Values:

$\chi=0.15, d f=1, p=.703$

$\mathrm{CFI}=1.000$

RMSEA Steiger-Lind's $=0.000$

${ }^{* * *} p<.001,{ }^{* *} p<.010,{ }^{*} p<.050$

Figure 5. The relationship between openness to experience, rumination and appreciation of life.

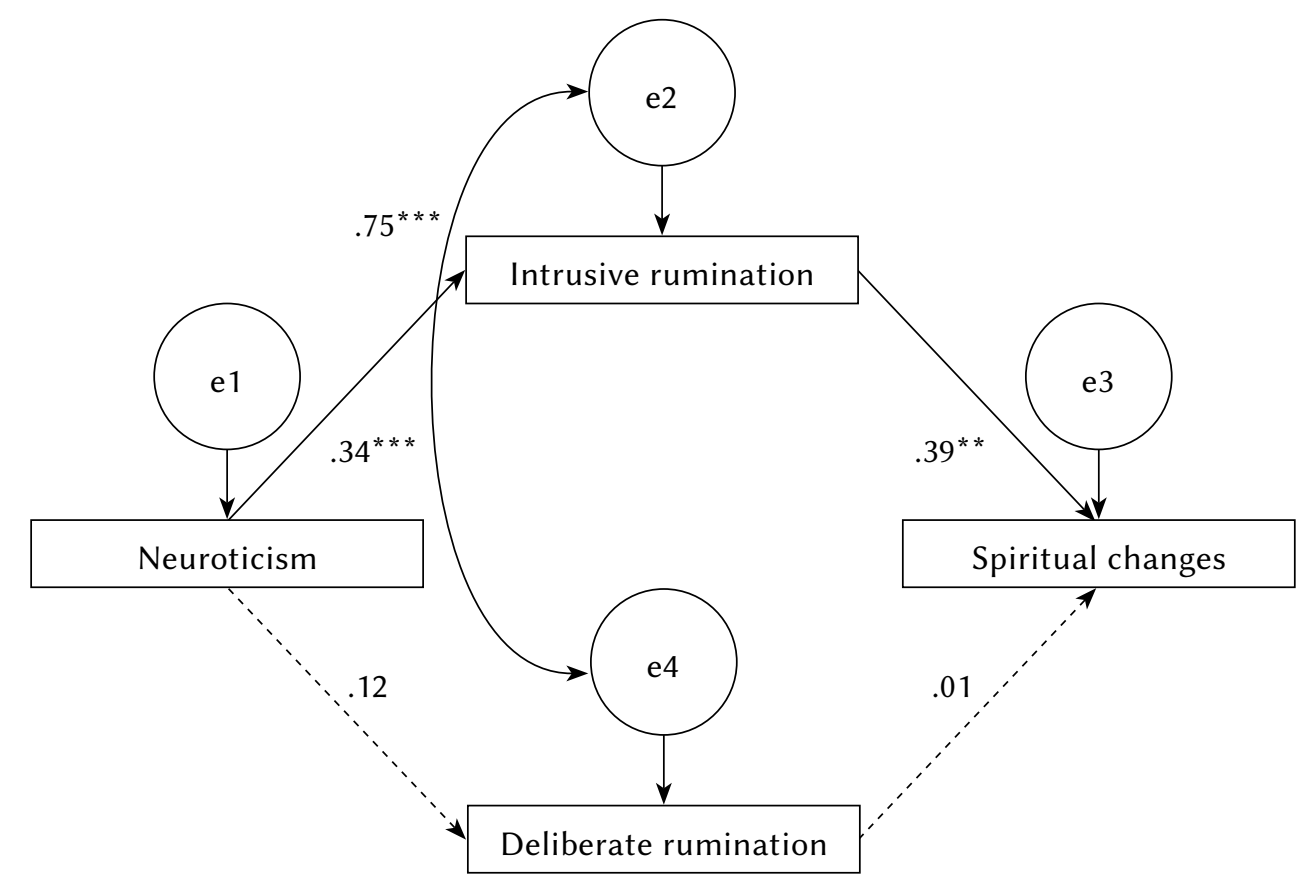

Values:

$\chi=0.01, d f=1, p=.923$

$\mathrm{CFI}=1.000$

RMSEA Steiger-Lind's $=0.000$

${ }^{* * *} p<.001,{ }^{* *} p<.010$

Figure 6. The relationship between neuroticism, ruminations and spiritual changes. 
ciated with intrusive rumination. Also, engaging in this form of rumination encourages the development of PTSD symptoms.

No significant relationship was found for two other aspects of personality, i.e. agreeableness and conscientiousness, and PTSD. Similarly, no significant relationship could be found between personality, rumination, and overall PTG score. However, personality and rumination were found to be related to two components of PTG: appreciation of life and changes in the spiritual realm (Figures 4-6).

Figure 4 presents the complex relationship existing between changes in appreciation of life, extraversion and rumination: Although no direct relationship was found between the degree of changes in appreciation of life and extraversion, appreciation of life was observed to be positively associated with both intrusive and deliberative rumination. Extraversion reduces the tendency to engage in intrusive rumination, but does not affect deliberative rumination. This suggests that by reducing this tendency for intrusive rumination, extraversion may indirectly reduce appreciation of life. A similar role is played by openness to experience (Figure 5). Openness to experience reduces the tendency to engage in intrusive rumination, but does not affect deliberate rumination.

Figure 6 presents the relationship between neuroticism, rumination and the occurrence of positive changes in the spiritual sphere. Neuroticism positively predicts intrusive rumination, which in turn increases the likelihood of changes in the spiritual sphere.

It is important to note that in all analysed models, positive associations were found between two forms of rumination, indicating that a greater tendency for intrusive rumination is accompanied by the tendency for deliberate rumination.

\section{DISCUSSION}

The findings indicate that while the experience of cancer can encourage the appearance of PTSD symptoms on the one hand, it may also be a source of PTG. Almost $77.70 \%$ of subjects demonstrated at least a medium degree of PTSD. Women and those who experienced illness in the recent period before the study, i.e. within five years, demonstrated a significantly higher level of these symptoms.

In addition, no subjects were observed to have any positive change resulting from the struggle with the disease, while $23.30 \%$ of them demonstrated a high level of positive posttraumatic changes. Women demonstrated a significantly greater level of PTSD symptoms than men, and a slightly greater level of PTG. The greatest changes were associated with appreciation of life. However, the proportion of subjects with a high level of PTG is lower than that identified in studies of female cancer patients following mastectomy, in which the proportion was found to be $50.00 \%$ (Ogińska-Bulik, 2010). The identified difference may be associated with the type of cancer. Craniofacial tumours, in comparison with breast cancer, presumably cause greater stress associated with significant changes in the appearance of the area around the face, resulting in a lower degree of positive posttraumatic changes.

In analysing the role of personality in the occurrence of negative outcomes of experienced trauma, it is necessary to determine the importance of three of its aspects: neuroticism, extraversion and openness to experience. Despite not being directly associated with the intensity of PTSD symptoms, they nevertheless appear to affect them indirectly. Neuroticism, by encouraging the tendency for intrusive rumination, indirectly increases the intensity of these symptoms. In contrast, extraversion and openness to experience reduce the tendency for this type of rumination, thus reducing the intensity of PTSD symptoms. This is consistent with the assumption concerning the relationship between neuroticism, intrusive rumination and PTSD.

No significant relationship was found between personality and rumination about the experienced event and PTG, taking into account the general results of PTGI. This is partly in contradiction with the assumption that extraversion and openness to experience are the personality factors that are associated with deliberate rumination and the occurrence of PTG. It indicates that both ruminating about an experienced event and occurrence of PTG are determined by factors other than personality traits.

However, a more detailed analysis revealed the presence of relationships with two components of PTG, i.e. appreciation of life and changes in the spiritual realm. It should be noted that the image of these relationships is a fairly complex one. Extraversion and openness to new experience reduce the tendency for intrusive rumination to occur and ruminations, both intrusive and deliberate, favour changes in appreciation of life and the spiritual sphere. Thus, both aspects of personality could indirectly influence positive changes in these aspects of PTG.

The role of neuroticism also appears to be an interesting one. Its association with intrusive rumination and PTSD appears to be an obvious one which has been noted in previous studies (Brodaty et al., 2004; Lawrence \& Fauerbach, 2003). However, through intrusive rumination, neuroticism also appears to favour positive changes in the spiritual sphere.

It is important to note that the effect of personality on PTSD and PTG cannot be reduced to that of susceptibility, merely the influence of personal characteristics on the positive and negative outcomes following trauma. Zawadzki, Kaczmarek, and Strelau (2009) note that in examining the nature of PTSD, it is important to consider also the complication effect, ex- 
pressed as the influence of PTSD on personal characteristics, the spectrum effect, as the mutual interaction between personality and PTSD. Similar postulates can be attributed to PTG, insofar as it is also possible that the survived trauma and its consequences may have an influence on the personality of the individual.

Regarding the novelty of the presented issues, it is important to emphasise the significance of rumination of the experienced event, in this case cancer, in the process of the occurrence of both the negative and the positive outcomes of the experienced trauma. Although intrusive rumination favours mainly the occurrence of PTSD, it may also foster positive changes in appreciation of life and the spiritual sphere. This is consistent with the assumption of Calhoun, Cann, and Tedeschi (2010) and Cann et al. (2011) that both types of ruminations are important for the occurrence of PTG. Intrusive rumination may play a positive role, by allowing some benefit to be gained from the experienced event. This form of rumination represents a prelude to deliberate rumination, acting to find ways of coping with the situation.

It is important to note that rumination about the experienced event may initially be associated with greater feelings of distress and negative emotions, especially when intrusive rumination predominates. However, later on, when intrusive rumination becomes more deliberate rumination, conditions favour the search for ways of coping with the event and its associated emotions, in effect serving to work through the trauma and foster positive changes (Calhoun, Cann, \& Tedeschi, 2010).

The occurrence of deliberative rumination, however, requires the passage of time (Helgeson, Reynolds, $\&$ Tomich, 2006). It is necessary to analyse the traumatic experience, and give it sense and new meaning, which as a consequence may lead to the occurrence of PTG.

It is important to mention that the significance of personality and rumination in the fostering of negative and positive effects of trauma may well be associated with the human capability for coping. This confirms studies indicating a positive association between rumination and coping strategies favouring the appearance of growth, such as positive revaluation, adopting problem-focussed strategies, turning to religion or giving sense to the experienced event (Cann et al., 2011).

The present study has some limitations. It is of a cross-sectional nature, which does not allow the cause-effect relationship to be unequivocally evaluated. It was performed on subjects who had experienced cancer at various times. The small sample limits the generalization of the results to the craniofacial cancer population. In addition, the study did not test whether the subjects had undergone any other events of a traumatic nature, and any changes were evaluated on a self-reporting basis, which may influence the results to some degree. However, despite its limitations, the obtained results add new content regarding the effects of events of a traumatic nature associated with the experience of a life-threatening disease. It may serve as inspiration for further studies, which should examine the role of the strategies chosen for coping with the illness.

Our findings may also have significance in practice, particularly in crisis interventions and in prophylactic programmes; such programmes should aim to build the skills to "work through" the experienced trauma by encouraging rumination over the event. Developing competence in coping with traumatic experiences may also be of value. It is important to remember that the occurrence of PTG also represents an opportunity to build resistance and a better ability to cope with future life challenges.

The findings allow us to formulate the following conclusions:

- Those who have experienced cancer demonstrate both negative and positive outcomes regarding PTSD symptoms and PTG.

- Although personality is not directly associated with PTSD or PTG, both may still exert an influence on the effects of trauma through rumination.

- Neuroticism increases the degree of PTSD by intrusive rumination. In contrast, extraversion and openness to experience reduce the intensity of these symptoms through their negative relationship with intrusive rumination.

- Neuroticism, by encouraging intrusive rumination, increases the possibility of occurrence of positive changes in the spiritual sphere.

- Extraversion and openness to experience indirectly reduce the degree of positive change with regard to appreciation of life and the spiritual sphere through intrusive rumination.

\section{ENDNOTES}

$1 \mathrm{~A}$ wider discussion regarding the understanding of the term and concept of rumination is presented in the article about the Polish adaptation of the event related rumination inventory (Ogińska-Bulik \& Juczyński, 2015).

2 The study was performed by a Master's seminar participant.

3 In accordance with the criteria established for the IES-R, the cut-off point was a value of 30 .

\section{References}

American Psychiatric Association (APA). (2013). DSM-5.http://dx.doi.org/10.1176/appi.books.9780890425596 
Bellizzi, K. M., \& Blank, T. O. (2006). Predicting posttraumatic growth in breast cancer survivors. Health Psychology, 25, 47-56.

Brodaty, H., Joffe, C., Luscombe, G., \& Thompson, C. (2004). Vulnerability to posttraumatic stress disorder and psychological morbidity in aged holocaust survivors. International Journal of Geriatric Psychiatry, 19, 968-979.

Calhoun, L. G., \& Tedeschi, R. G. (1998). Posttraumatic growth: Future directions. In R. G. Tedeschi, C. L. Park, \& L. G. Calhoun (eds.), Posttraumatic growth: Positive changes in the aftermath of crisis (pp. 215-238). New Jersey: Lawrence Erlbaum Associates.

Calhoun, L. G., \& Tedeschi, R. G. (2006). The foundations of posttraumatic growth: An expanded framework. In L. G. Calhoun \& R. G. Tedeschi (eds.), Handbook of posttraumatic growth (pp. 1-23). New Jersey: Lawrence Erlbaum Associates.

Calhoun, L. G., Cann, A., \& Tedeschi, R. G. (2010). The posttraumatic growth model: Sociocultural considerations. In T. Weiss \& R. Berger (eds.), Posttraumatic growth and culturally competent practice: Lessons learned from around the globe (pp. 1-14). New Jersey: John Wiley \& Sons.

Cann, A., Calhoun, L. G., Tedeschi, R. G., Triplett, K. N., Vishnevsky, T., \& Lindstrom, C. M. (2011). Assessing posttraumatic cognitive processes: the Event Related Rumination Inventory. Anxiety Stress \& Coping, 24, 137-156.

Carboon, I., Anderson, V. A., Pollard, A., Szer, J., \& Seymour, J. F. (2005). Posttraumatic growth following a cancer diagnosis: Do world assumptions contribute? Traumatology, 11, 269-283.

Chan, M. W., Ho, S. M., Tedeschi, R. G., \& Leung, C. W. (2011). The valence of attentional bias and cancer-related rumination in posttraumatic stress and posttraumatic growth among women with breast cancer. Psycho-Oncology, 20, 544-552.

Cordova, M. J., Studs, J. L., Hann, D. M., Jacobsen, P. B., \& Andrykowski, M. A. (2000). Symptom structure of PTSD following breast cancer. Journal of Traumatic Stress, 13, 301-309.

Costa, P., \& McCrae, R. R. (1989). NEO-PI/FFI. Manual Supplement. Odessa, FL: Psychological Assessment Resources.

Dudek, B. (2003). Zaburzenie po stresie traumatycznym [Posttraumatic stress disorder]. Gdańsk: GWP.

Dudek, B., \& Koniarek, J. (2004). Osobowościowe uwarunkowania rozwoju po stresie traumatycznym [Personality determinants of posttraumatic stress disorder]. In J. Strelau (ed.), Osobowość a ekstremalny stres [Personality and extreme stress] (pp. 183-198). Gdańsk: GWP.

Ehlers, A., \& Clark, D. M. (2000). A cognitive model of posttraumatic stress disorder. Behaviour Research and Therapy, 38, 319-345.

Ehring, T., \& Ehlers, A. (2014). Does rumination mediate the relationship between emotion regulation ability and posttraumatic stress disorder? Psychotraumatology, 5, 23547. http://dx.doi.org/10.3402/ ejpt.v.523547

Helgeson, V., Reynolds, K., \& Tomich, P. (2006). A meta-analytic review of benefit finding and growth. Journal of Consulting and Clinical Psychology, 74, 797-816.

Holeva, V., \& Tarrier, N. (2001). Personality and peritraumatic dissociation in the prediction of PTSD in victims of road accidents. Journal of Psychosomatic Research, 51, 687-692.

Jakšić, N., Brajković, L., Ivezić, E., Topić, R., \& Jakovljević, M. (2012). The role of personality traits in posttraumatic stress disorder (PTSD). Psychiatria Danubina, 24, 256-266.

Jeantieu, M., Gaillat, F., Antonini, F., Azoulay, E., Martin, C., Thomas, P., \& Leone, M. (2014). Postoperative pain and subsequent PTSD-related symptoms in patients undergoing lung resection for suspected cancer. Journal of Thoracic Oncology, 9, 362-369.

Juczyński, Z., \& Ogińska-Bulik, N. (2009). Pomiar zaburzeń po stresie traumatycznym - polska wersja zrewidowanej Skali Wpływu Zdarzeń [Measurement of post-traumatic stress disorder - Polish version of Impact of Event Scale-Revised]. Psychiatria, 6, 15-25.

Kangas, M., Henry, J. L., \& Bryant, R. A. (2002). Posttraumatic stress disorder following cancer: A conceptual and empirical review. Clinical Psychology Review, 22, 499-524.

Karanci, A. N., Işıklı, S., Aker, A. T., Gül, E. I., Erkan, B. B., Özkol, H., \& Güzel, H. Y. (2012). Personality, posttraumatic stress and trauma type: Factors contributing to posttraumatic growth and its domains in a Turkish community sample. European Journal of Psychotraumatology, 3, 17303. http:// dx.doi.org/10.3402/ejpt.v3i0.17303

Klonowicz, T., \& Eliasz, A. (2004). Traumatyczny stres w zawodowym doświadczeniu pracowników pogotowia. Rola niedopasowania osobowościowych regulatorów zachowania [Traumatic stress in the professional experience of emergency workers. The role of mismatch of personal regulators of behaviour]. In J. Strelau (ed.), Osobowość a ekstremalny stres [Personality and extreme stress] (pp. 167-182). Gdańsk: GWP.

Lawrence, J. W., \& Fauerbach, J. A. (2003). Personality, coping, chronic stress, social support and PTSD symptoms among adult burn survivors: a path analysis. Journal of Burn Care and Rehabilitation, 24, 63-72.

Linley, P. A., \& Joseph, S. (2004). Positive change following trauma and adversity: A review. Journal of Traumatic Stress, 17, 11-21.

Morris, B., \& Shakespeare-Finch, J. (2011). Rumination, post-traumatic growth, and distress: structural equation modeling with cancer survivors. Psycho-Oncology, 20, 1176-1183. 
Mystakidou, K., Tsilika, E., Parpa, E., Galanos, A., \& Vlahos, L. (2008). Post-traumatic growth in advanced cancer patients receiving palliative care. British Journal of Health Psychology, 13, 633-646.

Nolen-Hoeksema, S. (2000). The role of rumination in depressive disorders and mixed depressive/anxiety symptoms. Journal of Abnormal Psychology, 109, 504-511.

Ogińska-Bulik, N. (2010). Potraumatyczny rozwój w chorobie nowotworowej - rola prężności [Posttraumatic growth in cancer disease - the role of resiliency]. Polskie Forum Psychologiczne, 15, 125-139.

Ogińska-Bulik, N. (2015). Dwa oblicza traumy - negatywne i pozytywne skutki zdarzeń traumatycznych u pracowników stużb ratowniczych [Two faces of trauma - negative and positive effects of traumatic events in emergency service workers]. Warsaw: Wyd. Difin.

Ogińska-Bulik, N. (2016). Rola ruminacji w występowaniu pozytywnych zmian potraumatycznych u osób zmagających się z chorobami nowotworowymi [The role of rumination in occurrence of posttraumatic positive changes in people struggling with cancer]. Psychoonkologia, 20, 1-8.

Ogińska-Bulik, N., \& Ciechomska, M. (2016). Posttraumatic growth of parents struggling with cancer disease of their child - the role of rumination. Postępy Psychiatrii i Neurologii, 25, 99-110.

Ogińska-Bulik, N., \& Juczyński, Z. (2010). Rozwój potraumatyczny - charakterystyka i pomiar [Posttraumatic growth - characteristic and measurement]. Psychiatria, 7, 129-142.

Ogińska-Bulik, N., \& Juczyński, Z. (2015). Inwentarz Ruminacji o Negatywnym Zdarzeniu - polska adaptacja the Event Related Rumination Inventory [The Polish adaptation of the event related rumination inventory]. Przeglad Psychologiczny, 58, 383-400.

Park, C. L., Chmielewski, J., \& Blank, T. O. (2010). Posttraumatic growth: Finding positive meaning in cancer survivorship moderates the impact of intrusive thoughts on adjustment in younger adults. Psycho-Oncology, 19, 1139-1147.

Perez, S., Galdon, M. J., Andreu, Y., Ibanez, E., Dura, E., Conchado, A., \& Cardena, E. (2014). Posttraumatic stress symptoms in breast cancer patients: Temporal evolution, predictors and meditational models. Journal of Traumatic Stress, 27, 224-231.

Phipps, S., Jurbergs, N., \& Long, A. (2009). Symptoms of posttraumatic stress in children with cancer: Does personality trump health status. PsychoOncology, 18, 992-1002.

Salsman, J. M., Segerstrom, S. C., Brechting, E. H., Carlson, C. R., \& Andrykowski, M. A. (2009). Posttraumatic growth and posttraumatic stress disorder symptomatology among colorectal cancer survivors: A 3 month longitudinal examination of cognitive processing. Psycho-Oncology, 18, 30-41.
Shakespeare-Finch, J., Gow, K., \& Smith, S. (2005). Personality, coping and posttraumatic growth in emergency ambulance personnel. Traumatology, 11, 325-334.

Sheikh, A. I. (2004). Posttraumatic growth in the context of heart disease. Journal of Clinical Psychology in Medical Settings, 11, 265-273.

Shelby, R., \& Golden-Kreutz, D. (2008). PTSD diagnoses, subsyndromal symptoms and commorbidity contribute to impairments for breast cancer survivors. Journal of Traumatic Stress, 21, 165-172.

Strelau, J., Zawadzki, B., Oniszczenko, W., Sobolewski, A., \& Pawłowski, P. (2004). Temperament i style radzenia sobie ze stresem jako moderatory zespołu stresu pourazowego w następstwie przeżytej katastrofy [Temperament and styles of coping as moderators of posttraumatic stress disorder following a catastrophic event]. In J. Strelau (ed.), Osobowość a ekstremalny stres [Personality and extreme stress] (pp. 48-64). Gdańsk: GWP.

Taku, K., Calhoun, L. G., Cann, A., \& Tedeschi, R. G. (2008). The role of rumination in the coexistence of distress and posttraumatic growth among bereaved Japanese university students. Death Studies, 32, 428-444.

Tashiro, T., \& Frazier, P. (2003). "I'll never be in a relationship like that again”. Personal growth following romantic relationship breakups. Personal Relationship, 10, 113-128.

Tedeschi, R. G., \& Calhoun, L. G. (1996). The PostTraumatic Growth Inventory: Measuring the positive legacy of trauma. Journal of Traumatic Stress, 9, 455-471.

Tedeschi, R. G., \& Calhoun, L. G. (2004). Posttraumatic growth: Conceptual foundations and empirical evidence. Psychological Inquiry, 15, 1-8.

Weiss, D., \& Marmar, C. (1997). The Impact of Event Scale - Revised. In J. Wilson \& T. Keane (eds.), Assessing psychological trauma and PTSD: A handbook for practitioners (pp. 399-411). New York: Guilford Press.

Widera, A., Juczyński, Z., \& Popiela T. (2003). Psychologiczne wyznaczniki stresu pourazowego u pacjentów onkologicznych po okaleczających zabiegach chirurgicznych [Psychological determinants of post-traumatic stress in oncological patient after disabling surgical procedures]. Psychoonkologia, 7, 31-36.

Zawadzki, B., Kaczmarek, M., \& Strelau, J. (2009). Reaktywność emocjonalna a nasilenie objawów zaburzenia stresowego pourazowego u ofiar powodzi: efekt patoplastyczności, spektrum, podatności czy komplikacji [Emotional reactivity and severity of symptoms of posttraumatic stress disorder in flood victims: the effect of pathoplasticity, spectrum, vulnerability or complication]. In J. Strelau, B. Zawadzki, \& M. Kaczmarek (eds.), Konsekwencje psychiczne traumy: uwarunkowania 
i terapia [Psychological consequences of trauma: determinants and therapy] (pp. 77-109). Warsaw: Wyd. Naukowe Scholar.

Zawadzki, B., Strelau, J., Szczepaniak, P., \& Śliwińska, M. (1998). Inwentarz Osobowości NEO-FFI Costy i McCrae [Personality Inventory NEOFFI by Costa and McCrae]. Warsaw: Pracownia Testów Psychologicznych PTP. 